\title{
O TECNÓGENO NA CIDADE DE PRESIDENTE PRUDENTE-SP
}

\section{The Technogene in the city of Presidente Prudente, São Paulo, Brazil}

\author{
Érika Cristina Nesta Silva \\ Universidade Estadual Paulista "Júlio de Mesquita Filho", Presidente Prudente, São Paulo, Brasil \\ erikanesta@yahoo.com.br \\ João Osvaldo Rodrigues Nunes \\ Universidade Estadual Paulista "Júlio de Mesquita Filho", Presidente Prudente, São Paulo, Brasil \\ joaosvaldo@fct.unesp.br
}

Artigo recebido em 28/03/2013 e aceito para publicação em 30/06/2014

RESUMO: Uma forma de se observar as alterações humanas na superfície é por meio do estudo dos depósitos tecnogênicos. No caso de Presidente Prudente - SP foram estudadas duas formações tecnogênicas em planícies aluviais alteradas no entorno do perímetro urbano, nos seguintes loteamentos: Parque Residencial Francisco Belo Galindo e Vila Nova Prudente. Além de trabalhos de campo para o reconhecimento dos aspectos socioambientais, foram realizadas coletas de amostras dos depósitos tecnogênicos utilizando tubos de PVC de seis polegadas e com um metro de comprimento. Através dos trabalhos de campo e de análises físicas (texturais) realizadas em laboratório, identificou-se no Parque Residencial Francisco Belo Galindo, a presença de artefatos úrbicos (resquícios de concretos, plásticos, etc.) e material sedimentar, cuja classe textural predominante é "franco arenosa". No caso da Vila Nova Prudente, identificou-se também artefatos úrbicos (fragmentos de concretos, plásticos, etc.) e material sedimentar, cuja classe textural predominante é "areia". Com os dados obtidos nos levantamentos de campo e nas análises laboratoriais, foi possível a compreensão dos fatores presentes direta e indiretamente na formação dos depósitos tecnogênicos.

Palavras-chave: Tecnógeno, Depósitos Tecnogênicos, Natureza, Presidente Prudente-SP.

\begin{abstract}
One way to observe the human changes on the Earth surface is by studying the technogenic deposits. Concerning Presidente Prudente - SP, two technogenic formations in altered floodplains, surrounding the urban perimeter, in the following settlements were studied: Parque Residencial Francisco Belo Galindo and Vila Nova Prudente. Beside the fieldworks to recognition of the social environmental aspects, samples of technogenic deposits were collected using six-inch-PVC tubes, with one meter in length. Through the fieldworks and physical analyses (textural) performed in laboratory, it was identified the presence of urbic artifact (holdover of concrete, plastics, etc.) and sedimentary materials in Parque Residencial Francisco Belo Galindo, whose predominant textural class is "sandy loam". In Vila Nova Prudente, whose predominant textural class is "sandy", urbic artifacts (holdover of concrete, plastics, etc.) sedimentary materials were also identified. With the data obtained in the field survey and laboratorial analyses, it was possible to understand the direct and indirect presence of factors in the formation of technogenic deposits.
\end{abstract}

Keywords: Technogene, Technogenic Deposits, Nature, Presidente Prudente-SP. 


\section{INTRODUÇÃO}

Ao analisar o histórico de uso e ocupação e seus impactos na superfície no município de Presidente Prudente-SP percebe-se, cada vez mais, a ação da sociedade na modificação dos processos e dinâmicas de vários fenômenos naturais, principalmente na escala do local. Entre estas modificações podem ser citadas as observadas no ambiente urbano de Presidente Prudente, em especial onde ocorrem grandes adensamentos populacionais, nos quais os aspectos relacionados ao relevo, aos solos, a cobertura vegetal e a hidrodinâmica das águas superficiais e subterrâneas são alterados para que ocorra o aproveitamento quase por completo das áreas para construções.

As consequências das alterações humanas nos aspectos naturais têm se mostrado extremamente prejudiciais ao próprio ser humano. Não se pretende fazer apologia a visões catastróficas, mas mostrar que nas últimas décadas a preocupação com o próprio futuro da humanidade tem crescido mediante o reconhecimento de problemas ambientais, como a deposição inadequada dos resíduos sólidos, perda de solos agricultáveis devido a processos de contaminação e erosão acelerada, e a dificuldade crescente referente ao abastecimento de água potável por causa da contaminação e assoreamento de mananciais superficiais e de subsuperfícies.

Diversas áreas do conhecimento científico têm abordado os fenômenos e processos referentes à dinâmica da natureza e sua relação com a ação humana.

Uma questão importante refere-se à própria maneira como uma sociedade compreende a natureza, se ela é vista como um bem ou como um recurso a ser apenas apropriado. Estas perspectivas promovem formas de intervenção com resultados diferentes. E, de maneira geral, como a natureza tem sido vista pela sociedade atual?

No presente artigo, com base em estudo realizado em dois bairros da área urbana da cidade de Presidente Prudente (Parque Residencial Francisco Belo Galindo e Vila Nova Prudente), são discutidas questões referentes a esta interação historicamente estabelecida entre natureza e sociedade, bem como a emergência de uma nova época na escala de tempo geológica, o Tecnógeno, no qual a ação humana é responsável por sua determinação. Nos bairros estudados foram identificadas formações de depósitos tecnogênicos em áreas de planície aluvial alteradas. Estas formações são consideradas como testemunho da ação humana no local, constituindo-se como evidência da modificação nas características naturais destas planícies.

\section{ALGUMAS CONSIDERAÇÕES ACERCA DA RELAÇÃO SOCIEDADE-NATUREZAAO LON- GO DA HISTÓRIA}

As diversas sociedades, ao longo da história, têm demonstrado uma busca constante pelo suprimento de suas necessidades de sobrevivência. Esta busca tem ocasionado, conforme as dimensões socioculturais, impactos diferenciados aos ambientes. Neste sentido, com base nas ideias propostas por Camargo (2008), que trata das diferentes concepções de natureza,

[...] é certo que a construção do conceito de natureza não se prende apenas à apropriação capitalista da idéia de natureza, e que se associou à ciência normal. Pois o conceito de natureza alterna diferentes maneiras de se ver e se perceber o meio natural, tendo a construção desse complexo processo atravessado as diferentes escalas de percepção e de visão humana sobre a realidade (p.29).

Num primeiro momento pode ser citada a Revolução Neolítica, iniciada há aproximadamente 10.000 anos, com o início das transformações na natureza pelo ser humano. Isto devido a sua capacidade emergente de se sedentarizar, isto é, de se instalar num local. Contudo, cabe mencionar que este processo foi lento e ocorreu em períodos diferentes ao redor do mundo. Por exemplo, segundo Mazoyer e Roudart (2010), a agricultura neolítica teve início onde denomina de "oriente-próximo" (região que abrange a Síria e a Palestina) entre 10.000 e 9.000 anos antes do presente, e no norte da China (região do médio rio Amarelo) há aproximadamente 8.500 anos. Desta forma, conforme explica Oliveira (1990, p. 412), “[...] 
o Homem conquista as primeiras técnicas de produção de alimentos, deixando sua fase de coletor, na qual não se destacava do conjunto de atividades biológicas nas suas relações com a natureza". A partir deste período, o ser humano começa a modificar o seu entorno para melhor aproveitar as áreas de seus assentamentos e produções de gêneros alimentícios. Entretanto, a capacidade da natureza em retornar às suas condições originais ainda era, em boa parte, mantida.

Outro fato importante na história humana foi o aparecimento das primeiras cidades. De acordo com Sposito (1994), apesar da dificuldade em precisar o momento do surgimento das cidades, em geral aponta-se seu aparecimento por volta de 3.500 a.C. na Mesopotâmia, área que abarcava os rios Tigre e Eufrates, surgindo, posteriormente, no vale do Rio Nilo (3.100 a.C.), no vale do Rio Indo (2.500 a.C.) e Rio Amarelo (1.550 a.C.). Ainda, segundo a autora, as localizações das primeiras cidades tiveram como determinação as condições naturais, visto que as técnicas disponíveis não permitiam superar as imposições naturais. Assim, devido ao clima semi-árido predominante nas regiões de surgimento das primeiras cidades, havia a necessidade de fixação próxima aos rios (SPOSITO, 1994).

Durante a Idade Média (entre os séculos V e XV d.C.), conforme explica Camargo (2008), toda visão relacionada à natureza estava condicionada à ideologia cristã, ou seja,

\section{[...] No mundo medieval, Deus era a própria natureza em sua essência. Os segredos do am- biente eram segredos de Deus e do sagrado. Bruxarias, feitiços e vinganças divinas eram as causas de fenômenos que o homem despro- vido da fé não conseguia compreender. A fé seria algo incontestável e absoluto, servindo aos interesses da Igreja e dos poderosos de então [...] (CAMARGO, 2008, p. 36).}

Contudo, após o rompimento do feudalismo, a natureza passa a ser vista de modo racional. Para Camargo (2008), isso ocorre em conjunto com importantes acontecimentos econômicos, sociais e científicos. A estrutura produtiva e organizacional que nasce com o capitalismo, no qual a natureza passa a ser vista como fonte de lucro, é um importante exemplo mencionado pelo autor. No campo científico, a explicação sobre os fenômenos da natureza passa a ser menos relacionada às explicações religiosas. Entre os exemplos podem ser citados Galileu (1564-1642) na utilização da matemática para explicar a natureza; Francis Bacon (1561-1626) na proposição do método empírico indutivo "que se baseava em uma minuciosa observação atenta e isolada dos fenômenos por meio da sua experimentação contínua [...]" (CAMARGO, 2008, p.39); e René Descartes (1596-1650), na constituição de um método baseado na fragmentação, na matematização e na mecanização da natureza.

Com relação à tradição positivista, a natureza é vista como externa ao homem (CASSETI, 1991). Cabe mencionar que, a partir do predomínio do paradigma fragmentário da modernidade industrial, ou seja, desde a metade do século XIX, a Geografia foi praticamente trabalhada de forma dicotomizada (Geografia Física e Geografia Humana), sob forte tradição enciclopédica e imperialista sob a égide da filosofia positivista de August Conte, sendo uma ciência que teorizava e justificava o colonialismo, bem como suas novas conquistas territoriais. Desta forma, a visão de natureza nesta perspectiva dualista, ou seja, separada do ser humano, ocorre por três caminhos:

a) A "natureza" é estudada exclusivamente pela ciência natural, enquanto a ciência social preocupa-se exclusivamente com a sociedade, a qual não tem nada a ver com a natureza;

b) A "natureza" da ciência natural é supostamente independente das atividades humanas, enquanto a "natureza" da ciência social é vista como criada socialmente. Portanto, permanece uma contradição da natureza real, que incorpora a separação entre o humano e o não-humano; c) A terceira contradição dispersa a natureza humana dentro da natureza. O comportamento humano é regido pelo conjunto de leis que regulam os mais primitivos artrópodes. Essa visão determinista é defendida pelo darwinismo social e grande parte do behaviorismo. Na prática, observa-se que a natureza humana demonstra o seu domínio sobre as "leis da natureza" no processo de apropriação (CASSETI, 1991, p.11). 
Porém, cabe mencionar a importância de se estabelecer em diferentes estudos as relações entre natureza e sociedade, visto o reconhecimento da capacidade humana em alterar processos e dinâmicas naturais e, por estes, ser influenciado.

Um caminho possível, conforme trabalhado por Casseti (1991) é a teoria do materialismo histórico e dialético elaborada por Marx (1967). Assim,

\section{É através da transformação da primeira natureza em segunda natureza que o homem produz os recursos indispensáveis à sua existência, momento em que se naturaliza (a naturalização da sociedade) incorporando em seu dia-a-dia os recursos da natureza, ao mesmo tempo em que se socializa a natureza (modificação das condições originais ou pri- mitivas) (CASSETI, 1991, p. 11).}

Desta forma, tem-se a transformação da primeira natureza em segunda natureza, conforme menciona Casseti (1991), trabalhando as ideias de Marx. A primeira natureza é compreendida como aquela antes da intervenção do ser humano, a qual as transformações são regidas por processos endógenos (vulcanismos, tectonismos, etc.) e exógenos (ação dos fatores climáticos). Já a segunda natureza surge como resultado da transformação da primeira natureza através das forças produtivas da sociedade, ou seja, é a que apresenta características humanas em sua constituição.

Apesar da história demonstrar a capacidade humana de intervenção na natureza, é possível concluir que o grande salto ocorreu com a Revolução Industrial no século XVIII, em que Bortoluzzi e Petry (2008) apontam que o meio ambiente perde a sua capacidade de retornar às condições originais. A evolução técnica do ser humano ao longo da história possibilita esta maior intervenção na natureza.

O desenvolvimento de técnicas está relacionado com a busca de suprimento das necessidades humanas. No início da história da humanidade estas necessidades estavam relacionadas a questões básicas como moradia e alimento, ou seja, à sobrevivência. Contudo, com o advento da sociedade capitalista, outras necessidades foram criadas e estabelecidas.
De acordo com Porto-Gonçalves (2004), na sociedade capitalista o desenvolvimento das técnicas visa o aumento da produtividade. "Assim, numa sociedade como a capitalista, toda técnica tem que comportar essa dupla dominação: sobre a natureza e sobre os homens e mulheres ao mesmo tempo" (PORTO-GONÇALVES, 2004, p. 40).

O controle da produção da técnica, portanto, é exercido por poucos que determinam as intenções que a técnica deverá seguir. Desta forma, quem detém a capacidade técnica também detém o poder sobre determinados processos relacionados tanto à natureza quanto ao próprio ser humano.

Entretanto, sejam quais forem as técnicas, abrigarão em seu seio relações sociais e de poder. Afinal, se a técnica é meio, é preciso termos consciência dos fins que elas comportam; e, sendo a técnica uma busca de eliminação do acaso nas nossas ações, por meio dela sempre procuramos exercer um maior controle dos procedimentos e, assim, é nos procedimentos, tal como nos ensinara Michael Foucault, que se fazem as relações de dominação, de poder. As relações técnicas traduzem, em linguagem própria, as relações de poder da sociedade (PORTO-GONÇALVES, 2004, p.44).

Desta forma, retomando a discussão acerca das transformações na natureza executadas pelo ser humano, pode-se dizer que o desenvolvimento de determinadas técnicas estará relacionado direta ou indiretamente a essas modificações, tanto na questão da forma de intervenção na natureza, como em sua dimensão (temporal e espacial). Este fato pode ser observado, conforme o processo de intervenção, nos assentamentos humanos em áreas urbanas, por meio da execução de obras de engenharia civil mais sofisticadas em que, na atualidade, o ser humano possui a capacidade de modificar as condições originais do relevo e dos fluxos superficiais de água, formando ambientes tecnogênicos.

O que era inatingível fisicamente passa a ser alcançável através do domínio maior da chamada engenharia técnica de intervenção. Com 
isto, busca-se constantemente o detalhamento $d a$ "anatomia da natureza", para pretensamente saber construir, destruir, reconstruir novos espaços fisicos e sociais conforme os interesses econômicos e politicos dominantes para cada tempo histórico (SUERTEGARAY; NUNES, 2001, p. 17).

\section{O DESENVOLVIMENTO DAS TÉCNICAS PE- LAS SOCIEDADES}

No que dizem respeito à dimensão temporal e espacial, muitas técnicas de intervenção na natureza são difundidas na atualidade por um maior número de regiões do globo terrestre, bem como os resultados desta intervenção, seja ela prejudicial ou relacionada à recuperação ambiental, podem ultrapassar uma escala de tempo nunca vista antes na história da humanidade. Portanto, não ocorre um retorno a uma condição original da natureza, mas sim, a materialização de uma nova configuração espacial, cuja gênese está diretamente vinculada à presença humana.

Retomando a questão da forma de intervenção, o aparato técnico disponível a uma determinada sociedade tem fundamental importância. E o acesso da sociedade a determinadas técnicas é diferente conforme o momento histórico, a sociedade e as condições econômicas que esta possui.

A partir da Revolução Industrial até as sociedades contemporâneas, o desenvolvimento de novas técnicas cresceu numa velocidade maior do que anterior a este período. E com a possibilidade de acesso aos sistemas de comunicação, as informações sobre uma nova descoberta no campo científico são divulgadas rapidamente. Entretanto, entre o desenvolvimento e a socialização de uma nova técnica, há outros fatores considerados, como a própria sociedade e as condições econômicas.

No tocante às condições econômicas, muitas técnicas, apesar de poderem auxiliar uma parte considerável da população, ainda ficam contidas nas mãos de poucos grupos, como técnicas relacionadas à produção de medicamentos e outras. Contudo, seria superficial admitir-se apenas o fator econômico na produção e concentração da técnica. Questões políticas e sociais também estão envolvidas.
Numa sociedade constituída por relações sociais e de poder contraditórias, as técnicas trazem embutidas suas contradições sociais e políticas. Aqui, a idéia de que há intencionalidade impregnada nas técnicas (Santos, 1996) ganha um outro sentido, radical: é que, estando a sociedade constituída por relações contraditórias, a intencionalidade traduz-se em técnicas que comportam não só as suas contradições, mas diferentes potencialidades contraditoriamente possiveis (PORTO-GONÇALVES, 2004, p. 38).

Como exemplo, o autor menciona as técnicas jurídicas e pedagógicas existentes para que todos aceitem a ideia da propriedade privada como sagrada e natural.

Outra questão relacionada é o próprio desenvolvimento (ou não) de técnicas. Desta forma, a própria produção científica passa, em muitos casos, pelos mandos e desmandos do capital.

Enfim, com a ciência e a técnica se tornando uma força produtiva de capital, uma série de pesquisas que seriam de interesse público não são realizadas, como o impacto nos diferentes ambientes da introdução de novas substâncias químicas ou de novas espécies para que se possa analisar a poluição química elou biológica. [...] Assim, mais do que diante de um tempo antrópico que muitos procuram distinguir dos tempos da natureza, estamos diante de uma temporalidade própria do capital, em que time is money (PORTO-GONÇALVES, 2004, p.50).

Com relação à própria sociedade, há ainda um caráter a ser trabalhado. É a questão de apesar de se considerar a existência de várias formas de se viver, por meio do reconhecimento de diferentes culturas existentes (e até mesmo sociedades passadas), ainda procura-se, de modo geral, alcançar um modelo de desenvolvimento apenas baseado num padrão europeu-ocidental. Esta ideia de desenvolvimento está atrelada à ideia de dominação da natureza. 
[...] Desenvolvimento é o nome-síntese da idéia de dominação da natureza. Afinal, ser desenvolvido éser urbano, é ser industrializado, enfim, é ser tudo aquilo que nos afaste da natureza e que nos coloque diante de constructos humanos, como a cidade, como a indústria. [...] Por fazerem a crítica a essa idéia-chave de desenvolvimento, os ambientalistas, com freqüencia, se vêem acusados de querer voltar ao passado, ao estado de natureza, enfim, de ser contra o progresso e o... desenvolvimento (PORTO-GONÇALVES, 2004, p. 24).

Aqui temos a retomada da questão da forma de se conceber a natureza. Ou seja, neste modelo de desenvolvimento mencionado, há uma anulação dos saberes de várias comunidades, como a indígena, a qual possui uma forma de se relacionar com a natureza não pautada na dominação em busca do mencionado modelo de progresso ou desenvolvimento. A natureza, portanto, nestes moldes, é vista como objeto de dominação. E como tal, faz-se necessário o invento e utilização de técnicas relacionadas a este fim. Estas técnicas têm sido desenvolvidas rapidamente e empregadas em diferentes lugares, em especial nos locais de maior concentração humana, onde o que se observa é o maior incremento de objetos artificiais e uma maior transformação da natureza.

A velocidade de criação de novos equipamentos tecnológicos de intervenção na dinâmica da natureza, a partir da lógica de valorização dos recursos naturais como mercadorias, tem gerado significativas transformações/degradações no relevo. Estas transformações têm sido mais evidenciadas nos locais de maiores concentrações populacionais, em que o capital intensifica sua atuação na busca da obtenção de maior lucratividade (SUERTEGARAY; NUNES, 2001, p. 17).

Esta velocidade e capacidade de transformação da natureza causada pelo ser humano, têm levado a discussões acerca das diferenças no tempo que faz e no tempo que escoa (SUERTAGARAY; NUNES, 2001). Desta forma, o tempo que escoa é visto como o tempo profundo, como por exemplo, o tempo relacionado à morfogênese do relevo. De acordo com Serres (1994, apud SUERTEGARAY; NUNES, 2001), este consiste num tempo linear, com seu reconhecimento obtido pelos valores médios. Já o tempo que faz, é o tempo relacionado à morfodinâmica do relevo; é o tempo das oscilações, das irregularidades, dos ritmos e da ação antrópica. "É também um tempo que introduz no que fazer da natureza a dimensão antropogênica, não levada em conta quando nos detemos a refletir na ótica do tempo que escoa" (SUERTEGARAY; NUNES, 2001, p. 19).

Ao reconhecer a capacidade do ser humano em se constituir como um fator responsável por alterações nos aspectos e dinâmicas da natureza, surge um novo viés de estudo que considera a existência de uma nova época geológica, o Tecnógeno.

\section{O ADVENTO DO TECNÓGENO}

Conforme explica Ter-Stepanian (1988), mencionado por Peloggia (1998), o Holoceno pode ser considerado como uma época de transição entre o Quaternário (Pleistoceno) e o Quinário ou Tecnógeno, denominações que, conforme desenvolvido a seguir, possui diferenças. Devemos observar, entretanto, que esta transição é gradual, ainda está em processo e depende de vários fatores, como o histórico, o econômico, e outros.

Cabem aqui algumas considerações acerca das denominações "Quinário" e "Tecnógeno". De acordo com Oliveira (2005), numa ilustração cronológica da proposta conceitual de Ter-Stepanian (1988), o Quinário seria um periodo geológico e o Tecnógeno sua época correspondente. A explicação elaborada por Peloggia (2003) elucida esta questão.

No entanto, de maneira geral, quando nos referimos ao "periodo" Tecnógeno tratamos de um intervalo de tempo geológico, por assim dizer, informal. Mas já se faz necessário, neste momento, uma definição mais rigorosa de seu significado. Deve ser notado em primeiro lugar que a denominação "Quinário" implica necessariamente em estatuto de sistema (representando assim um período), 
porque é indicativa de posição estratigráfica em seqüencia - superior ao Quaternário e ao Terciário, nomenclaturas também definidas dessa forma. Apesar de não ter absolutamente duração extensa, pode sem dúvida constituir unidade de referência, por ser facilmente reconhecida mundialmente (tornando-se a exigência temporal para este requisito também inexigivel), porque é a unidade atual. De fato, a relação espacial, neste caso, é evidência simples e óbvia da posição cronoestratigráfica e idade relativa (Lei de Steno).

Já a denominação de Tecnógeno, por sua vez, traz menos problemas formais, por não indicar posição seqüencial e por sua riqueza de referência ao conteúdo material, como já tem sido destacado (e.g. Oliveira, 1995). Pode, assim, ser incluída - posição que opinamos mais apropriada - como série (representando, portanto, uma época) do Quaternário ou Antropógeno (PELOGGIA, 2003, p. 4).

Desta forma, no presente ensaio, adota-se o termo "Tecnógeno", visto a sua referência ao conteúdo material que, no caso trabalhado, pode ser relacionado com os depósitos tecnogênicos.

Entre as principais evidências da existência do Tecnógeno estão, portanto, os chamados depósitos tecnogênicos, conceito adotado no campo da Geologia e definido por Chemekov (1983), conforme mencionado por Peloggia (1998). Estes são considerados como marcos estratigráficos relacionados à ação humana (PELOGGIA, 1996). Constitui, portanto, “[...] uma classe de formação superficial gerada em decorrência da atividade geológica humana" (PELOGGIA, 2003, p. 1). Desta forma, o ser humano pode ser considerado um agente geológico devido a sua capacidade de alterar e produzir processos relacionados à dinâmica superficial, inclusive produzindo este tipo de depósito, correlativo a suas ações. (PELOGGIA; OLIVEIRA, 2005).

É em virtude desse estatuto que o homem pode ser considerado um agente geológico de caráter essencialmente novo e diferenciado: ele é capaz de fazer as propriedades e o modo de ser da natureza combinarem-se de maneira original, em novos modos de funcionamento, de forma subordinada a suas intenções (PELOGGIA; OLIVEIRA, 2005, p. 1).

Além de agente geológico, o ser humano pode ser considerado como agente geomorfológico, pois consegue alterar diversos aspectos do relevo de forma mais rápida se comparado aos efeitos das dinâmicas naturais. As afirmações de Nir (1983), acerca do homem enquanto agente geomorfológico, em muito se assemelha com a explicação do homem como agente geológico. Um dos exemplos é a questão da modificação das características do solo pelo ser humano e a consequente intensificação de processos erosivos.

Outro ponto fundamental nas considerações elaboradas por Nir (1983) é a questão da intensidade de intervenção não ocorrer de maneira semelhante em toda a superfície terrestre, ou seja, é diferente de acordo com o país ou região, com o período histórico e o tipo de sociedade. Aqui, entre os fatores influentes, pode-se relacionar a questão já mencionada acerca de como uma determinada sociedade concebe a natureza, sendo este um dos pontos a ser considerado na elaboração e execução das formas de intervenção na natureza.

Ao observar os aspectos trabalhados anteriormente, pode-se considerar como inegável a dimensão humana na transformação das paisagens. No Brasil, os principais estudos que abordam o ser humano como agente geológico datam a partir da década de 1990, como os trabalhos de Oliveira (1990) e Peloggia (1996).

Outra questão relacionada aos depósitos tecnogênicos refere-se à classificação destas deposições e a capacidade de se formarem por meio de ações humanas diretas e indiretas. Em alguns locais, os depósitos tecnogênicos apresentam características semelhantes aos solos formados por processos naturais. Contudo, ao realizar-se uma análise local mais detalhada, identifica-se a presença de materiais manufaturados e sedimentares de origem antrópica.

Desta forma, existem diferentes tipos de classificações para os depósitos tecnogênicos, conforme os parâmetros estratigráficos, genéticos, dos materiais constituintes e outros. 
Entre as principais classificações utilizadas destaca-se a de Fanning e Fanning (1989) para os "solos altamente influenciados pelo homem", trabalhada por Peloggia (1996) da seguinte forma:

1)Materiais "úrbicos" (do inglês urbic): tratam-se de detritos urbanos, materiais terrosos que contêm artefatos manufaturados pelo homem moderno, freqüentemente em fragmentos, como tijolos, vidro, concreto, asfalto, pregos, plástico, metais diversos, pedra britada, cinzas e outros, provenientes por exemplo de detritos de demolição de edifícios; 2)Materiais "gárbicos" (do inglês garbage, lixo): tratam-se de depósitos de material detrítico com lixo orgânico, de origem humana e que, apesar de conterem artefatos em quantidades muito menores que a dos materiais úrbicos, são suficientemente ricos em matéria orgânica para gerar metano em condições anaeróbicas.

3)Materiais "espólicos" (do inglês spoil, despojo): materiais terrosos escavados e redepositados por operações de terraplanagem em minas a céu aberto, rodovias ou outras obras civis. Contêm muito pouca quantidade de artefatos, sendo identificados pela expressão geomórfica "não natural", ou ainda por peculiaridades texturais e estruturais em seu perfil.

4)Materiais "dragados": materiais terrosos provenientes da dragagem de cursos d'água e comumente depositados em diques em cotas topográficas superiores às da planície aluvial (PELOGGIA, 1996, p.60-61).

Esta classificação parte do princípio da identificação dos tipos de material que são encontrados no depósito tecnogênico. Porém, a presença de determinados materiais na superfície está condicionada a ações especificas de intervenção. Por exemplo, os materiais úrbicos podem ser depositados principalmente nas fases em que está em processo a consolidação da ocupação urbana. Já os materiais espólicos poderão estar relacionados a ações de modificação em aspectos do relevo, como nos processos de terraplanagens. Nes- te caso, é imprescindível o conhecimento da história de transformação da paisagem, pois pode ocorrer o erro de considerar os sedimentos oriundos deste processo como de origem unicamente "natural", sem a intervenção humana, devido à ausência de materiais manufaturados, que são um dos principais indícios da ação tecnogênica.

No que concerne ao tipo de ação responsável pela constituição do depósito, uma das principais referências é Oliveira (1995, p.233), que aborda três tipos principais, os "construídos (aterros, corpos de rejeito, etc.); induzidos (assoreamento, aluviões modernos, etc.) e modificados ("depósitos" naturais alterados tecnogenicamente por efluentes, adubos, etc.)". Este autor trabalhou os processos relacionados à formação de depósitos tecnogênicos no Planalto Ocidental Paulista.

Os depósitos tecnogênicos podem ser reconhecidos tanto em ambiente urbano quanto no rural. Entretanto, é no ambiente urbano que ocorre a maior presença dos artefatos de origem humana decorrente do elevado grau de modificação da paisagem e, consequentemente, geração de diversificados materiais. Especificamente nas áreas das planícies aluviais, por serem áreas receptoras de materiais transportados de montante, são onde se encontram com maior facilidade os depósitos tecnogênicos. Este fato tem sido observado nas planícies aluviais de Presidente Prudente-SP durante os trabalhos de campo para reconhecimento dos aspectos da paisagem e, posteriormente, mediante coleta e análise de amostras desses depósitos tecnogênicos em laboratório. Alguns exemplos são trabalhados na sequência do presente artigo. Cabe mencionar que a paisagem aqui está sendo considerada a partir da conjunção de elementos naturais e sociais.

De nosso ponto de vista, percebemos paisagem como um conceito operacional, ou seja, um conceito que nos permite analisar o espaço geográfico sob uma dimensão, qual seja o da conjunção de elementos naturais/tecnificados, socioeconômicos e culturais (SUERTEGARAY, 2000. p.22). 


\section{O CASO DAS PLANÍCIES TECNOGÊNICAS DA CIDADE DE PRESIDENTE PRUDENTE-SP}

O estudo dos depósitos tecnogênicos permite algumas analogias com termos advindos da geografia, geomorfologia e geologia. Um dos exemplos, conforme trabalhado por Peloggia (1998), é a questão da planície tecnogênica. Segundo o autor,

Deve ser ressaltado, neste aspecto, que a expressão geomórfica básica deste relevo de agradação pós-quaternário consiste no recobrimento homogêneo, isto é, a desfiguração da antiga compartimentação das várzeas (cinturão meândrico, planície inundável, terraços escalonados). Assim, a rigor, também a de- nominação genérica de "aluviões recentes", empregada para designar os sedimentos das planicies holocênicas, deve ser substituída pela de "aluviões pré-recentes" (PELOGGIA, 1998, p.90).

Em Presidente Prudente, estas formações foram observadas e estudadas em dois bairros, uma no Parque Residencial Francisco Belo Galindo e outra na Vila Nova Prudente (Figura 1). Segundo Silva (2012), com o aumento da área urbana, há uma maior possibilidade de formação dessas planícies tecnogênicas, como nos casos estudados.

Contudo, apesar de estudadas nestes dois locais, a formação de planícies tecnogênicas na referida cidade não se restringe a eles.

Figura 1: Localização da cidade de Presidente Prudente e das planícies tecnogênicas estudadas.

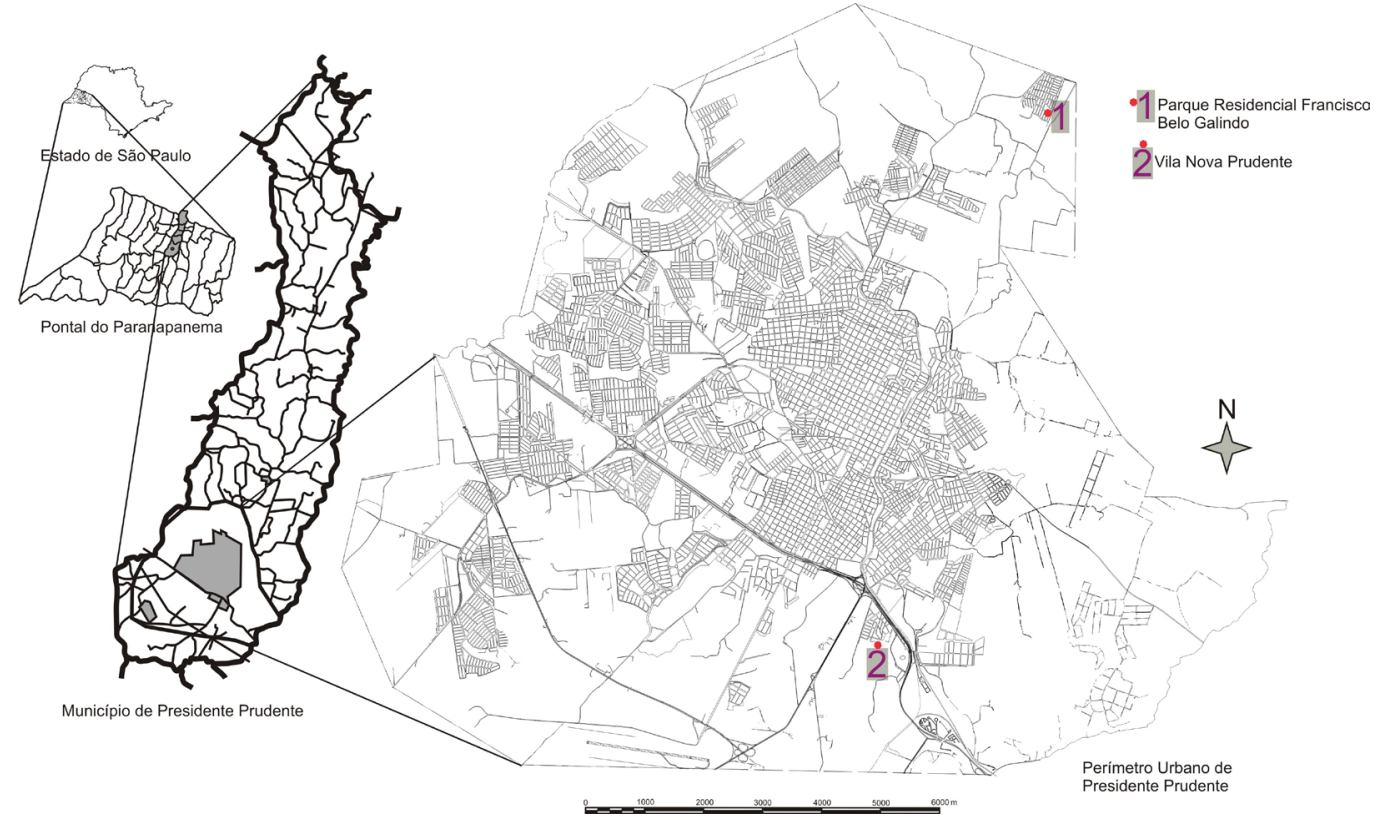

Fonte: Adaptado de Silva, 2012.

O processo de expansão urbana realizado na cidade de Presidente Prudente ocasionou diversas alterações na morfologia original do relevo, em especial nas áreas das planícies aluviais. Além do relevo, estas modificações inseriram elementos artificiais antropizados nas paisagens, alterando aspectos naturais como as características da cobertura vegetal, dos cursos d'água e escoamento superficial. Estes são os casos do Parque Residencial Francisco Belo Galindo e da Vila Nova Prudente.

O Parque Residencial Francisco Belo Galindo, localizado no setor norte do perímetro urbano, surge em continuidade a outro bairro, o Jardim Morada do Sol (Figura 2). Neste último, apesar de ter sido aprovado em 1992 (FERNANDES, 1998), a maioria da população chegou ao loteamento apenas entre 1997 e 1999, devido à falta de infraestruturas básicas, conforme menciona Silva (2008). 
Figura 2: Modificação nos aspectos da área do Jardim Morada do Sol e Parque Residencial Francisco Belo Galindo. Comparação entre os anos de 1995 e 2010.

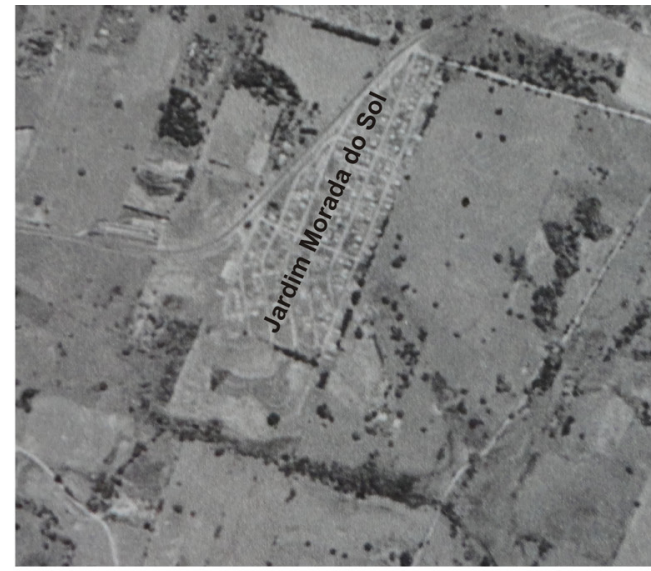

Recorte de foto aérea- Empresa BASE S.A., 1:25.000, Set/95; Fx.04 n.08

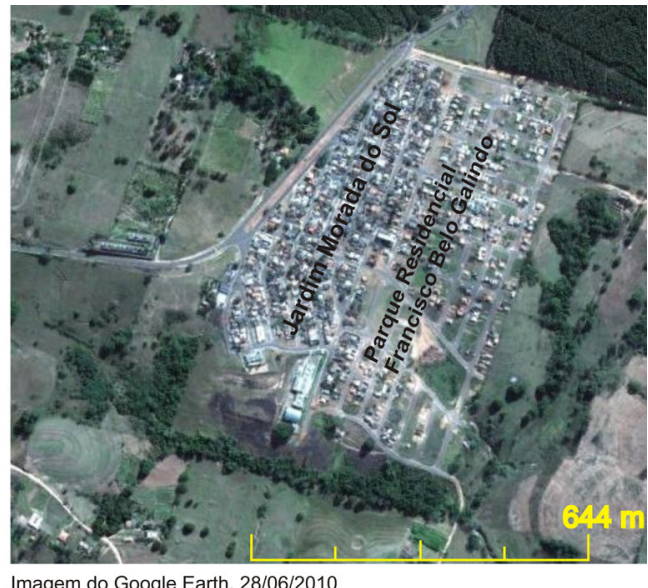

Imagem do Google Earth, 28/06/2010

Fonte: Silva, 2012.

No decorrer do processo de ocupação de ambos os loteamentos, as características físicas do local foram alteradas, inclusive com a retirada da cobertura vegetal original e, no caso do loteamento do Parque Residencial Francisco Belo Galindo, ocupou-se áreas próximas à planície aluvial e cursos d'água.

Desta forma, diversos materiais manufaturados e sedimentares foram depositados na área da planície aluvial, de forma direta pela população, e indireta, condicionada pelo arraste através do fluxo superficial de água. Assim, houve a formação de uma planície tecnogênica no local estudado, na qual se procedeu a coleta de uma amostra do depósito tecnogênico com as características demonstradas na Figura 3. A coleta ocorreu com o auxílio de um tubo de PVC de seis polegadas e com um metro de comprimento, penetrado à percussão no corpo do depósito tecnogênico. $\mathrm{O}$ tubo de PVC foi aberto em laboratório e o volume coletado foi suficiente para o reconhecimento das camadas de deposição através de parâmetros como cor e material presente, bem como para as análises realizadas com parcelas de cada uma das camadas de deposição. Para a classificação textural das camadas foram utilizados procedimentos adaptados de EMBRAPA (1997), relacionados à análise granulométrica, por intermédio da qual foram reconhecidas as porcentagens de areia, silte e argila das amostras. As porcentagens foram transpostas para o Diagrama Textural proposto pelo USDA(1951, apud LEMOS; SANTOS, 1996) (Figura 4).

Figura 3. Perfil da amostra de depósito tecnogênico do Parque Residencial Francisco Belo Galindo e texturas reconhecidas em cada camada de deposição.

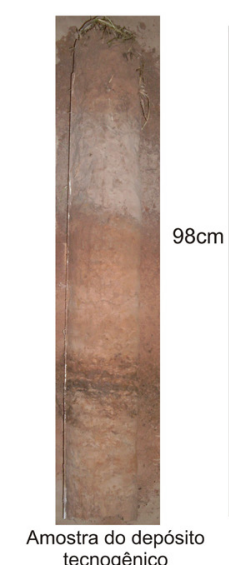

tecnogênico

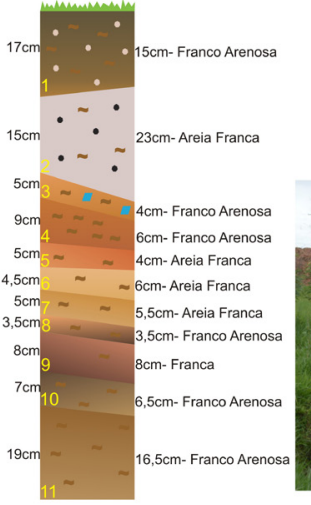

Fonte: Adaptado de Silva, 2012.
Artefatos/Estruturas

$\because$ Argamassa e/ou Cimento

$\because$ Resquício de queimada

z Matéria orgânica e/ou raizes \# Plásticos

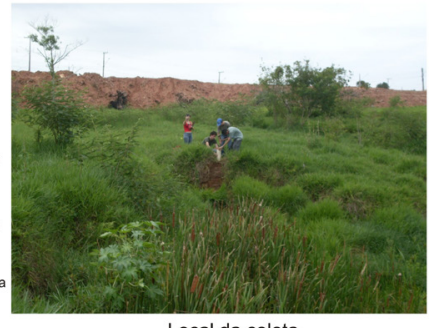

Local da coleta 
Figura 4. Diagrama Textural proposto pelo U.S.D.A.

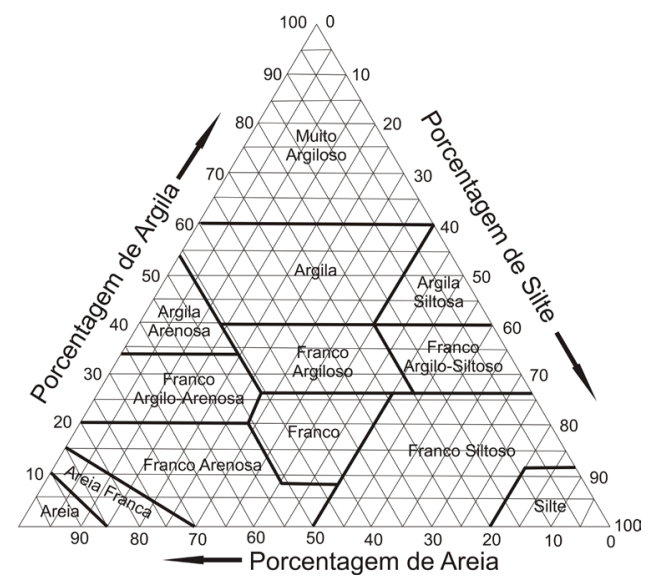

Fonte: U.S.D.A. (1951) apud Lemos e Santos (1996).

Nas amostras analisadas em campo e no laboratório, identificou-se a presença de materiais úrbicos, principalmente materiais de construção civil e plásticos, conforme pode ser observado nas camadas superiores 1 e 3 (Figura 3). Já as camadas mais profundas apresentaram sedimentos com características diferentes dos comumente encontrados em áreas de planície. Ao considerar fatores como o histórico de uso e ocupação, concluiu-se que estas camadas também são tecnogênicas, sendo os sedimentos transportados de montante. Trata-se, portanto, de uma área com constituição de uma planície tecnogênica.

A segunda planície tecnogênica estudada localiza-se na Vila Nova Prudente. Este loteamento é mais antigo que o anteriormente estudado, datando de 1964 (SPOSITO, 1990). Entre 1995 e 2010 não ocorreram grandes transformações na área, ao contrário do observado na Figura 2 referente ao loteamento do Parque Residencial Francisco Belo Galindo. No entanto, a formação de depósitos tecnogênicos na área foi mais evidente devido à quantidade de materiais tecnogênicos manufaturados depositados no interior da planície, além do escoamento evidente de águas servidas (Figura 5). Além disso, o curso d'água presente em diferentes mapeamentos consultados não foi observado no interior desta planície devido ao processo degradativo de assoreamento.

Figura 5. Área da planície tecnogênica na vila Nova Prudente. Destaques para deposições de materiais tecnogênicos e escoamentode águas servidas.

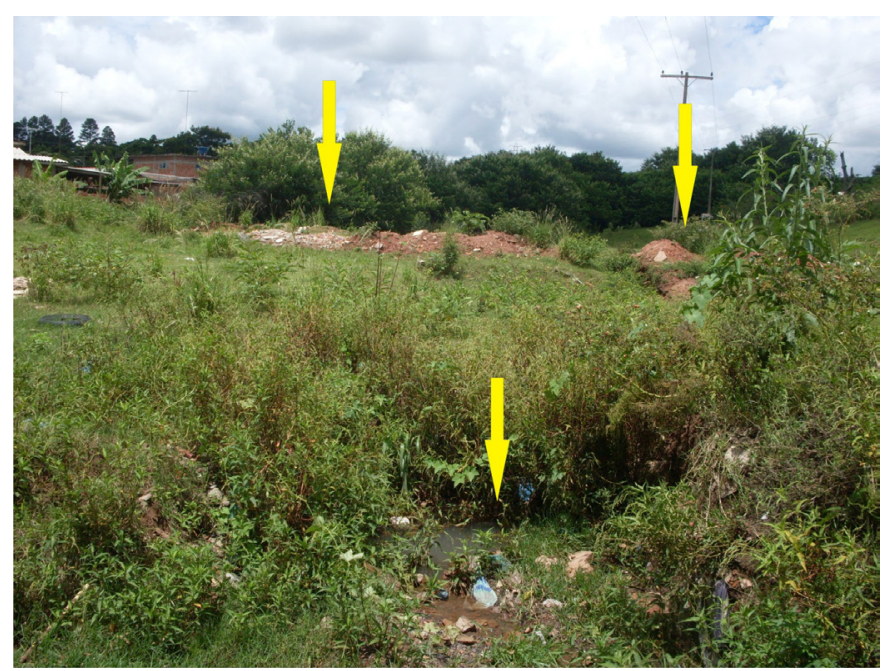

Fonte: Silva, 2012. 
Neste caso específico, as adjacências da planície tecnogênica apresentaram dois tipos de usos do solo: um urbano, no setor norte, relacionado à ocupação residencial, e outro rural, devido à presença da atividade de criação de gado e pastagem nos setores sul, oeste e leste da planície. Desta forma, o depósito tecnogênico, bem como a amostra coletada do mesmo (Figura 6), apresentou indícios destas duas formas de uso e ocupação. Os procedimentos adotados de coleta e análise foram os mesmos do depósito anteriormente citado.

Figura 6. Perfil da amostra de depósito tecnogênico da Vila Nova Prudente e texturas reconhecidas em cada camada de deposição.
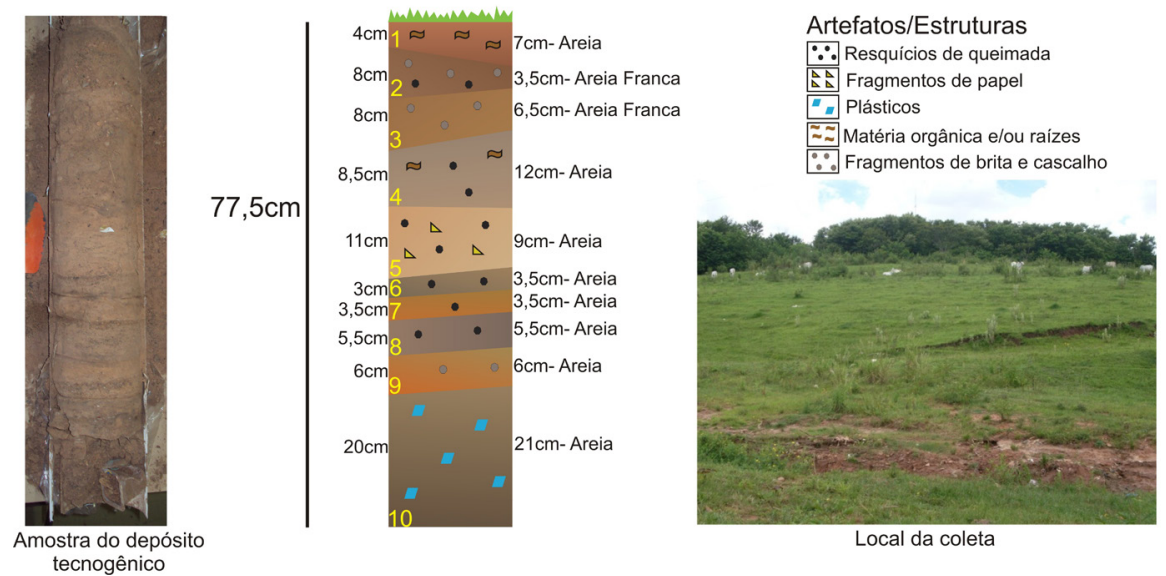

Adaptado de Silva, 2012.

Desta forma, os elementos presentes na amostra foram reconhecidos enquanto indícios da ação humana no entorno da planície. Primeiro, notou-se quantidade elevada de materiais tecnogênicos manufaturados, principalmente materiais de construção e plásticos (materiais úrbicos), não somente na superfície da planície tecnogênica, mas em camadas mais profundas, conforme pode ser observado na camada 10 da amostra coletada (Figura 6). Isto mostra que todas as camadas acima da décima são tecnogênicas, ou seja, no mínimo, a profundidade da planície tecnogênica é de $77,5 \mathrm{~cm}$, baseado na amostra de depósito tecnogênico coletada.

Outra questão observada é a presença de fragmentos de queimadas em diversas camadas de deposição. A queimada é um fator importante observado nas formas de uso e ocupação, pois tanto no processo de ocupação do Planalto Ocidental Paulista, conforme evidenciado por Oliveira (1995) e Monbeig (1984), quanto nos dias atuais, ocorreram e ainda ocorrem queimadas. Pode-se mencionar, pelo menos para o caso estudado, que os resquícios de queimadas são antrópicos, devido à verificação deste tipo de ação em diferentes locais do perímetro urbano, bem como a presença, no depósito, de materiais manufaturados, sendo este mais um indício de interferência humana na constituição destas camadas.

Quanto à textura, reconheceu-se uma porcentagem elevada de areia, inclusive uma quantidade de areia grossa superior ao depósito tecnogênico do Parque Residencial Francisco Belo Galindo. Esta quantidade maior de areia, responsável pela predominância da classe textural "areia", foi relacionada aos materiais de construção encontrados no interior da planície, ou seja, relacionada aos materiais úrbicos identificados.

As duas planícies tecnogênicas estudadas demonstraram o acúmulo de materiais tecnogênicos em áreas de fundos de vale. De acordo com Lei Complementar $\mathrm{n}^{\circ}$ 153/2008 que dispõe sobre a Lei de Zoneamento do Uso e Ocupação do Solo da área urbana do Município de Presidente Prudente, as áreas dos dois loteamentos são destinadas para uso residencial, sendo isto observado nos trabalhos de campo e, também, nos tipos de materiais encontrados nos depósitos tecnogênicos (materiais úrbicos, relacionados a construções). Contudo, as áreas onde se encontram os depósitos estudados, ou seja, áreas de fundo de vale, são destinadas a "Preservação e Proteção Ambiental", conforme a mesma Lei, mas o que se observou foram áreas degradadas, com a ausência da 
cobertura vegetal original, processo de assoreamento e deposição de materiais tecnogênicos.

Estes dois exemplos foram mencionados aqui para demonstrar como a sociedade tem a capacidade de modificar as características naturais de um local, e este processo pode proporcionar a formação de novas coberturas sobre a superfície: os chamados depósitos tecnogênicos. Estes, mesmo que os tipos de uso e ocupação se alterem nos locais estudados, vão se constituir como indícios de ocupações pretéritas, evidentes, principalmente, pelos tipos de materiais tecnogênicos manufaturados identificados.

\section{CONCLUSÃO}

Foram abordados neste artigo alguns aspectos da relação sociedade-natureza ao longo da história humana. Esta relação está pautada por diversos fatores, dentre eles, a forma como uma determinada sociedade, num dado momento histórico, compreende o que é a natureza e qual a sua importância para o ser humano.

Em Presidente Prudente foram levantados alguns aspectos desta relação por meio do estudo dos depósitos tecnogênicos em áreas de planícies aluviais. Dada as alterações observadas, essas planícies foram denominadas de tecnogênicas, visto não se tratar mais de planícies tipicamente holocênicas.

Pelo estudo dos materiais presentes na planície tecnogênica do Parque Residencial Francisco Belo Galindo, em consonância com a história de uso e ocupação, foi possível creditar a formação das camadas mais profundas a períodos nos quais as construções eram incipientes ou ainda não existentes, ocorrendo o contrário com as camadas mais superficiais, devido a presença de materiais gárbicos. Já no caso da Vila Nova Prudente, mesmo as camadas mais profundas apresentaram materiais manufaturados possíveis de serem encontrados após o início da ocupação dos lotes, fato relacionado ao histórico do bairro ser mais antigo, bem como a possibilidade de descarte de materiais na área do fundo de vale ser mais intensa. Em ambos os casos, observa-se a relação da sociedade com a natureza não pautada pela busca de conservação ou preservação dos componentes naturais, especialmente dos solos e cursos d'água.

Neste aspecto, o estudo da abordagem tecnogênica possibilita o reconhecimento concreto da ação humana nos diferentes ambientes, principalmente nas áreas urbanas fortemente modificadas ao longo da história. Além disto, os estudos sobre depósitos tecnogênicos permitem a reflexão teórica e metodológica de formas alternativas de uso não predatório das paisagens.

\section{AGRADECIMENTOS}

A FAPESP (Fundação de Amparo à Pesquisa do Estado de São Paulo). À equipe do Laboratório de Sedimentologia e Análise e Solos da FCT/UNESP.

\section{REFERÊNCIAS}

BORTOLUZZI, E. C.; PETRY, C. Partículas minerais: da rocha ao sedimento. In: POLETO, C. (Org.). Ambiente e Sedimento. Porto Alegre:ABRH, 2008. p.1-38.

CAMARGO, L. H. R. A Ruptura do Meio Ambiente. Conhecendo as mudanças ambientais do planeta através de uma nova percepção da ciência: a Geografia da Complexidade. 2.ed. Rio de Janeiro: Bertrand Brasil, 2008.

CASSETI, V. Ambiente e apropriação do relevo. São Paulo: Contexto, 1991.

EMBRAPA. Manual de métodos de análise de solos. 2. ed. Rio de Janeiro, 1997. 212 p. Il. (EMBRAPA-CNPS. Documentos, 1).

FERNANDES, S. A. S. Territorialização das políticas habitacionais em Bauru e Presidente Prudente: A atuação da CDHU, Cohab-CRHIS e Cohab-Bauru. 1998. 248f. Dissertação (Mestrado em Geografia) Faculdade de Ciências e Tecnologia, Universidade Estadual Paulista, Presidente Prudente, 1998.

MAZOYER, M.; ROUDART, L. História das agriculturas no mundo: do neolítico à crise contemporânea. Tradução: Cláudia F. Falluh Balduino Ferreira. São Paulo: Editora UNESP; Brasília; DF: NEAD, 2010.

MONBEIG, P. Pioneiros e fazendeiros de São Paulo. Tradução: Ary França e Raul de Andrade e Silva. São Paulo: Hucitec, 1984. 
NIR, D. Man, a geomorphological agent: an introduction to anthropic geomorphology. Jerusalem: Keper Publishing House, 1983.

OLIVEIRA, A. M. S. A Abordagem Geotecnogênica: a Geologia de Engenharia no Quinário. In: BITAR, O. Y. (coord.). Curso de Geologia aplicada ao Meio Ambiente. ABGE:IPT, 1995. p. 231-241.

OLIVEIRA, A. M. S. Depósitos tecnogênicos associados a erosão atual. In: Congresso Brasileiro de geologia de Engenharia, 6, 1990, Salvador. In: VI CBGE e IX COBRAMSEF. Salvador, 1990. Anais... Salvador: ABGE/ ABMS, 1990. p.411-416.

OLIVEIRA, A. M. S. et al. Tecnógeno: registro da ação geológica do homem. In: SOUZA, C. R. G. et. al. (ed.). Quaternário do Brasil. Ribeirão Preto: Holos, 2005.

PELOGGIA, A. U. G. Delineação e aprofundamento temático da geologia do tecnógeno do município de São Paulo: as conseqüências geológicas da ação do homem sobre a natureza e as determinações geológicas da ação humana em suas particularidades referentes à precária ocupação urbana. 1996, 162f. Tese (Doutorado em Geociências) - Instituto de Geociências, Universidade de São Paulo, São Paulo, 1996.

PELOGGIA, A. U. G. O homem e o ambiente geológico: geologia, sociedade e ocupação urbana no município de São Paulo. São Paulo: Xamã, 1998.

PELOGGIA, A. U. G. O problema estratigráfico dos depósitos tecnogênicos. In: II CONGRESSO SOBRE PLANEJAMENTO E GESTÃO DAS ZONAS COSTEIRAS DOS PAÍSES DE EXPRESSÃO PORTUGUESA; IX CONGRESSO DAASSOCIAÇÃO BRASILEIRA DE ESTUDOS DO QUATERNÁRIO; II CONGRESSO DO QUATERNÁRIO DOS PAÍSES DE LÍNGUAIBÉRICAS. Recife, 2003. Anais... Recife, 2003. Disponível em: <http://www.abequa.org.br/ trabalhos/projeto_43.pdf>. Acesso em: 05 mai. 2012.

PELOGGIA,A. U. G.; OLIVEIRA,A. M. S. Tecnógeno: um novo campo de estudos das geociências. In: X CONGRESSO ABEQUA, Guarapari, 2005. Anais...
Guarapari, 2005. Disponível em: $<$ http://www.abequa. org.br/trabalhos/0268_tecnogeno.pdf>. Acesso em: 05 mai. 2012.

PORTO-GONÇALVES, C. W. O desafio ambiental. Rio de Janeiro: Record, 2004.

PRESIDENTE PRUDENTE (Prefeitura Municipal). Lei Complementar $n^{\circ} 153 / 2008$. Dispõe sobre a Lei de Zoneamento do Uso e Ocupação do Solo, da Área Urbana do Município de Presidente Prudente e dá outras providências. Disponível em: $<$ http://www.presidenteprudente.sp.gov.br/site/ Documento?cod=612>. Acesso em 01 de junho de 2012.

SILVA, E. C. N. Formação de depósitos tecnogênicos e relações com o uso e ocupação do solo no perímetro urbano de Presidente Prudente - SP. 2012. 183 f. Dissertação (Mestrado em Geografia). Faculdade de Ciência e Tecnologia, Universidade Estadual Paulista, Presidente Prudente, 2012.

SILVA, F. C. A Segregação Socioespacial no Jardim Morada do Sol em Presidente Prudente-SP. Monografia (bacharelado em Geografia). 2008. 177 f. Faculdade de Ciência e Tecnologia, Universidade Estadual Paulista, Presidente Prudente, 2008.

SPOSITO, E. S. Produção e apropriação da renda fundiária urbana em Presidente Prudente. Tese (Doutorado em Geografia), 1990. 230 f. Faculdade Filosofia Letras e Ciências Humanas, Universidade de São Paulo, São Paulo, 1990.

SPOSITO, M. E. B. Capitalismo e urbanização. 5. ed. São Paulo: Contexto, 1994.

SUERTEGARAY, D. M. A.; NUNES, J. O. R. Anatureza da Geografia Física. Terra Livre. São Paulo. n¹7, p. 11-27, 2001.

SUERTEGARAY, D. M. A. Espaço geográfico uno e múltiplo. In: SUERTEGARAY, D. M. A.; BASSO, L. A.; VERDUM, R. (org). Ambiente e Lugar no urbano: a Grande Porto Alegre. Porto Alegre: UFRGS, 2000. 